\title{
Adalete İlişsin Hassasiyetlerin Gelişimsel İzleri: Haksızlıktan Kaçınma Davranışına İlişkin Güncel İncelemeler*
}

\section{Developmental Hints of Fairness Sensitivity: Current Investigations on Inequity Avoidance Inequity Avoidance}

\author{
Büșra Aktaș ${ }^{1}$ (])
}

"Yazar notu: Makalenin yazım sürecinde gösterdikleri değerli destek ve önerileri için Dr. Öğr. Üyesi Hasan Galip Bahçekapılı, Prof. Dr. Sevim Cesur ve Doç. Dr. Mehmet Harma'ya teşekkürlerimi sunarım.

'Doktora Öğrencisi, İstanbul Üniversitesi

ORCID: B.A. 0000-0002-0125-7903

Sorumlu yazar/Corresponding author: Büşra Aktaş,

İstanbul 29 Mayıs Üniversitesi, Edebiyat Fakültesi, Psikoloji Bölümü İstanbul, Türkiye

E-posta/E-mail: baktas@29mayis.edu.tr

Başvuru/Submitted: 26.10 .2020

Kabul/Accepted: 21.01.2021

Online Yayın/Published Online: 07.07.2021

Citation/Atıf: Aktas, B. (2021). Adalete İlişkin Hassasiyetlerin Gelişimsel İzleri: Haksızlıktan Kaçınma Davranışına İlişkin Güncel

İncelemeler. Psikoloji Çalışmaları - Studies in

Psychology, 41(2), 403-425.

https://doi.org/10.26650/SP2020-816658
ÖZ

Adalete ilişkin karar alma ahlak psikolojisi alan yazınında en önemli konulardan biri olarak kabul edilmektedir. Bulgular, kişilerin diğerlerinden daha azına (dezavantajlı haksızlık) veya daha fazlasına sahip oldukları durumlarda (avantajlı haksızlık) adalete ilişkin hassasiyetlerinden ötürü bedel ödeyerek haksızlığı reddettiklerini göstermektedir. Gelişimsel psikoloji alanındaki incelemelere göre haksızlıktan kaçınma olarak adlandırılan bu davranışın ortaya çıkmasının altında farklı mekanizmalar rol oynayabilir. Haksızlıktan kaçınma davranışının ortaya çıktığı yaşa ilişkin kültürel farklılıkları inceleyen çalışmalar, farklı kültürlerde dezavantajlı haksızlıktan kaçınma davranışının benzer bir gelişimsel seyre sahip iken; avantajlı haksızlıktan kaçınmanın farklı yaşlarda ortaya çıktığını göstermektedir. Bu durum, avantajlı haksızlıktan kaçınma davranışının ortaya çıktığ1 yaşa ilişkin sosyalleşme pratiklerinin ve kültürel faktörlerin rolünün daha baskın olduğuna işaret etmektedir. Buna paralel olarak, bu derleme çalışmasında öncelikle, güncel ahlak psikolojisi alan yazınındaki adalete ilişkin hakim yaklaşımlara değinilmiş, ardından haksızlıktan kaçınma davranışını gelişimsel boyutta ele alan çalışmalar kültürel farklar gözetilerek özetlenmiştir. Birlikte ele alındığında, önceki çalışmalar haksızlıktan kaçınma davranışına ilişkin stratejilerin zenginleşmesini yaşla beraber sosyal bağlamın ve itibar kaygısının rolünün artmasıyla açıklamaktadır. Buradan hareketle, farklı kültürlerde farklı sosyal pratiklerin itibar kaygısını azaltmada işlevsel bir rolü olduğu ve bu durumun özellikle avantajlı haksızlıktan kaçınma davranışına ilişkin davranışların gelişimsel seyrinde kültürlerarası farklara yol açtığı düşünülmektedir. Bununla birlikte, güncel çalışmaların sonuçları ele alındığında, bu dinamiklerin anlaşılması için bireyci ve toplulukçu ikili sınıflandırması üzerinden yapılan açıklamaların yetersiz kaldığ 1 görülmektedir. Gelecek çalışmalarda bireyci ve toplulukçu ikili sınıflandırması üzerinden yapılan açıklamaların ötesine geçebilmek için, toplumdaki belirli sosyalleşme dinamiklerinin rollerini, ailedeki ebeveyn beklentilerini ve akrabalarla yaygın olarak kabul gören sosyal etkileşim uygulamalarının rollerini daha detaylı incelemenin ilgili alana önemli ölçüde katkı sunması beklenmektedir.

Anahtar Kelimeler: Ahlak psikolojisi, adalet, haksızlıktan kaçınma davranışı, ahlaki gelişim 


\section{ABSTRACT}

Fairness-based decision-making is considered one of the most crucial topics in the literature on moral psychology. Previous findings have demonstrated that people make costly irrational decisions according to their level of fairness sensitivity. Moreover, individuals display inequity avoidance behavior by rejecting inequity favoring others (disadvantageous inequity) or themselves (advantageous inequity). According to developmental investigations, different mechanisms may underlie the display of advantageous or disadvantageous inequity avoidance. Previous studies have indicated that in various cultures, disadvantageous inequity avoidance follows a similar path, whereas advantageous inequity avoidance emerges at different ages. These findings have pointed out that socialization practices and cultural factors may be dominant in terms of the age of onset of advantageous inequity avoidance. In parallel, this review first presents the pioneer approaches to fairness in the recent literature on moral psychology and provides a summary of developmental studies that investigated inequity avoidance behavior by considering cultural differences. In summary, the literature has proposed that social context and reputational concerns may encourage children to adopt better strategies for displaying inequity avoidance with the increasing age. From this perspective, this notion was considered to lead to crosscultural differences in the developmental spectrum of behaviors particularly linked to advantageous inequity avoidance. This finding may be attributed to different social practices across cultures that are considered to play a functional role in reducing reputational concerns. Moreover, explanations based on collectivistic versus individualistic dual perspective are unable to explicate various specific dynamics for understanding the age of onset of the display of inequity avoidance behavior. Therefore, further studies are required to reveal the roles of specific socialization dynamics in the community, parental expectations, and widely accepted social interaction practices with relatives, which would largely contribute to the relevant literature.

Keywords: Moral psychology, fairness, inequity avoidance, moral development

\section{EXTENDED ABSTRACT}

Fairness is an essential concept for understanding human morality. According to recent findings, the avoidance of having less than others may be a universally important sensitivity, which is consistent with the assumptions of cooperation-based theories (Brosnan \& de Waal, 2012). By contrast, the avoidance of having more than others may be related to increased sensitivity to social norms and cultural expectations regarding the emergence of this sensitivity (McAullife, Blake, Steinbeis, \& Warneken, 2017). However, the concept promoting the development (or delay) of gaining sensitivity toward unfairness to others is still unknown. The current frameworks of moral psychology describe the moral reasoning related to fairness from the perspective of the evolution of reciprocal altruism (Trivers, 1971). Scholars define fairness as a solution to the bargaining problem (Curry, 2016; Haidt, 2001). In addition to the frameworks intended to enhance the understanding of fairness-related moral reasoning, Fehr and Schmidt (1999) proposed two behavioral forms of fairness sensitivity, namely, avoidance of having less than others (disadvantageous inequity avoidance) and avoidance of having more than others (advantageous inequity avoidance).

Distributive fairness is one of the most studied forms of fairness. However, developmental information is required to further understand its role in human cooperation. Similarly, the 
number of studies that examine fairness sensitivity during infancy is increasing (Burns \& Sommerville, 2014; Geraci \& Surian, 2011; Lucca, Pospisil, \& Sommerville, 2018; Schmidt \& Sommerville, 2011). Seemingly, fairness-related sensitivities appear to emerge considerably earlier than previously assumed (Kohlberg, 1981). For example, Meristo, Strid, and Surian (2015) demonstrated that even infants at 10 months can distinguish fair and unfair resource allocations. As such, future studies are required to clarify the mixed evidence obtained from the existing research, which posits that fairness expectations are in place during infancy (e.g., Burns \& Sommerville, 2014; Geraci \& Surian, 2011; Lucca et al., 2018). Although emerging fairness expectation is a starting point, displaying fair behaviors certainly requires in-depth investigation. Numerous previous findings have illustrated that children aged 4-5 years start to display the avoidance of having less than others (Blake \& McAuliffe, 2011; Takagishi, Kameshima, Schug, Koizumi, \& Yamagishi, 2010; see also Bereby-Meyer \& Fiks, 2013). According to recent findings, disadvantageous inequity avoidance may emerge during early childhood (LoBue, Nishida, Chiong, DeLoache, \& Haidt, 2011). By contrast, findings related to the age of onset of advantageous inequity avoidance behavior are mixed. For example, a recent study reports that among seven countries, only children from the United States, Canada, and Uganda (but not from India, Mexico, Peru, and Senegal) rejected gaining more than peers during childhood. Various investigations demonstrated similar results. Moreover, children from Turkey (Acun \& Karakelle, 2019) and China (Kajanus, McAuliffe, Warneken, \& Blake, 2019) display avoidance of gaining more than peers during childhood. In summary, cross-cultural evidence suggests that disadvantageous inequity avoidance is consistently evident during childhood with less cultural variability. Therefore, avoidance of gaining less than others may be a universally crucial sensitivity consistent with the assumptions of cooperation-based explanations (Brosnan \& de Waal, 2012). Alternatively, advantageous inequity avoidance may be more sensitive to social norms and cultural expectations regarding its emergence (McAullife, Blake, Steinbeis, \& Warneken, 2017). A body of evidence gained from collectivistic cultures has suggested that children display inequity avoidance at a younger age (Kajanus et al., 2019), whereas other studies put forward that children from collectivistic cultures display inequity avoidance at a later age (Blake et al., 2015). These findings may motivate researchers to re-think the definition of the term cultural.

\section{Discussion}

Although the individualistic/collectivistic dual classification is one of the most referred dimensions for explaining cultural variations, this cultural classification seemingly provides a poor explanation for the emergence of fairness-related sensitivities. In other words, further investigations must exceed individualistic/collectivistic dual perspectives to explain cultural 
variations in relation to the emergence of inequity avoidance. Therefore, expecting that gaining sensitivity to unfairness to others is closely related to social practices, family attitudes, relationship dynamics, and social context is reasonable. In this manner, determining the age of onset of displaying inequity avoidance is necessary by specifically considering the social context. 
Güncel ahlak kuramlarının açıklamaları, ahlaki karar almayı bilişsel kapasitenin zenginleşmesi ve sosyalleşme becerilerinin gelişimi ile yavaş ve kademeli bir ilerlemenin ürünü olarak gören yaklaşımlardan (Damon, 1981; Kohlberg, 1976; Piaget, 1932/1968) farklı varsayımlar barındırır. Güncel kuramların sosyal sezgiselci bakış açısına göre, adalet evrimsel olarak işbirliğinin güçlendirilmesinde ve işbirliğine ilişkin problemlerin çözümünde rol sahibi olan adaptif bir motivasyon şeklinde açıklanır (Curry, 2016; Haidt ve Graham, 2007; Tomasello ve Vaish, 2013). Sosyal sezgiselci yaklaş1min paralelinde, bebeklik ve erken çocukluk döneminde adalet hassasiyetini inceleyen çalışmalar çoğalmaktadır (LoBue, Nishida, Chiong, DeLoache ve Haidt, 2010; Sloane, Baillargeon ve Premack, 2012). Bu derleme makalesinde, adalet hassasiyetinin anlaş1masından başlayarak haksızlıktan kaçınmanın davranışsal olarak sergilenmesine dek geçen süreç, kültürlerarası farklar gözetilerek gelişimsel bir boyutta incelenmiştir. Çalışmalar, dezavantajlı haksızlıktan kaçınmanın evrensel şekilde ve çoğu kültürde benzer yaş dönemlerinde ortaya çıkarken, avantajlı haksızlıktan kaçınma davranışının hangi yaşta kazanıldığının kültürel farklılıklara daha açık olduğunu göstermektedir (Blake ve ark., 2015). Bu sebeple, dezavantajlı haksızlıktan kaçınma davranışının evrimsel olarak işbirliği için önemli bir motivasyon görevi gördüğü ve evrensel bir ahlaki hassasiyet olarak erken dönemlerde ortaya çıktığı, ancak avantajlı haksızlıktan kaçınma için sosyalleşme pratiklerinin desteğinin daha önemli olduğu düşünülmektedir. Yapılan incelemelerin çoğunlukla Batılı kültürlerden elde edilen verilerden oluşması, özellikle avantajlı haksızlıktan kaçınma davranışının sergilenmesinde etkili olan sosyal faktörlerin anlaşılması için daha fazla çalışmaya ihtiyaç olduğuna işaret etmektedir. Bu çalışmada, haksızlıktan kaçınma davranışına dair mevcut bilgilerin gelişimsel boyutta ele alınmasının yanında, bu davranışın gelişiminde kültürel farkların etkisinin göz önünde bulundurulduğu bir değerlendirme sunmak hedeflenmiştir.

\section{Güncel Ahlak Psikolojisi Alan Yazınında Adalet Hassasiyeti}

İnsan davranışını anlamada önemli role sahip olan adalet, ahlak psikolojisi alan yazınında birçok incelemenin temel yapıtaşlarından olmuştur. Bu çalışmaların çerçevesini oluşturan en meşhur kuramlardan birisi Lawrence Kohlberg'in (1981) bilişsel gelişimsel ahlak kuramıdır. Kohlberg'in ahlak kuramı, Batılı felsefe temelinde kurulmasının yarattığı yanlılıklar, ahlaki akıl yürütmeyi basamaklı bir ilerleyişle ele alması, ahlakın yalnızca bilişsel yönüne odaklanması ve ahlaki akıl yürütmede rasyonellik varsayımı dolayısıyla eleştirilmiştir (Carpendale, 2000; Gilligan, 1982; Snarey, 1985). Bu eleştiri- 
ler, bugün ahlak alan yazınında güncel ahlak kuramlarının tekçi ahlaki bakış açısından çoğul ahlaki bakış açısına doğru evirilmesine katkı sağlamış olabilir (Cesur, 2018). Ahlaki karar almada güncel bir bakış açısı sunan Haidt’a (2001) göre, klasik kuramlar 'duygusal köpeğin rasyonel kuyruğuna' odaklanan ahlaki muhakemeye yönelik açıklamalar yapmakla beraber sezgisel ve duygusal süreçlerin baskın rolünü atlamaktadır Haidt $(2001$; 2007) buradan hareketle sosyal sezgisel modeli öne sürer. Buna göre, ahlaki karar vermede rasyonel süreçler önemli olmakla birlikte, evrimsel kökleri olan hassasiyetler kişileri karşılaşılan ahlaki durumlarda otomatik tepkiler vermeye yöneltir. Hem insanlarda hem diğer bazı memelilerde adaletten uzaklaşılan durumların olumsuz tepkilerle karşılandığını gösteren çalışmalar adalet hassasiyetine ilişkin evrimsel temelli açıklamalara destek sağlar (Brosnan ve de Waal, 2014). Ancak her ne kadar adalete ilişkin hassasiyetlerin açıklanmasında işbirliğinin evrimine dayanan açıklamalar önemli ölçüde bilgi sunsa da, ahlaka ilişkin davranış ve tutumların gelişimi doğası gereği bağlam ve kültürel değerlere oldukça içkin bir yapıya sahiptir (Rai ve Fiske, 2011). Bu sebeple, ahlaki tutum ve davranışlara ilişkin evrimselci ve doğuştancı açıklamaların test edilmesinde, sosyalleşme pratiklerinin göz önünde bulundurulması ve gelişimsel olarak ortaya çıkmasında bu pratiklerin destekleyici veya engelleyici unsurlar olarak değerlendirmeye tabi tutulması, ilgili kavramların aydınlatılmasında oldukça önemlidir (Kağıtçıbaş1, 2012; Rai ve Fiske, 2011).

Psikoloji çalışmalarında adalete ilişkin tutumlar yaygın olarak hipotetik senaryolar (Haidt ve Graham, 2007; Kohlberg, 2008) ve davranışsal olarak ekonomi oyunları arac1lığıyla test edilir (Engel, 2011; Güth, Schmittberger ve Schwarze, 1982). Ekonomi oyunu çalışmalarında kişilerden kaynak dağılımlarını gerçekleştirmeleri veya halihazırda gerçekleştirilmiş kaynak dağılımlarının kabulü veya reddine ilişkin karar vermeleri istenir. Klasik ekonomide, kişilerin bir homo economicus gibi düşünerek tercihte bulunacağı ve kazancın maksimize edilmesine yönelik firsatları her durumda kabul edeceği varsayılır. Ancak çalışmalarda kişilerin farklı parametreleri gözeten, rasyonellikten uzak ancak adil olanı sağlamaya yönelik tercihlerde bulunduğu görülmektedir (Fehr ve Schmidt, 1999). Diğer bir deyişle, kişiler adil olmak ve çıkar sağlamak arasında bir tercihte bulunduğunda dengeli bir strateji gütmeyi tercih eder. Oyun kuramının test edildiği çalışmalarda dünden bugüne temel araç olarak kullanılmış iki meşhur oyun Ültimatom

1 (Bu konuda yayımladığı makalesi orijinal ismiyle "The emotional dog and its rational tail: A social intuitionist approach to moral judgment" şeklindedir). 
Oyunu ve Diktatör Oyunudur (Güth ve ark., 1982; Kahneman, Knetsch ve Thaler, 1986). Yapılan çalışmalarda aktör tarafından alıcıya sunulan miktarın \%20’nin altında olduğu durumlarda alıcı rolündeki kişilerin parayı kabul etmeye gönüllü olmadığı görülür (Camerer, 2003; Fehr ve Schmidt, 1999; Güth ve ark., 1982). Bu davranışı açıklayan hipotezlerden birisi insanların adil bir dünyada yaşamayı tercih ettikleri ve bu adalet hassasiyetiyle adil davranmayanları cezalandırarak işbirliğini güçlendirmeyi amaçladıklarını öne sürer (Kahneman ve ark., 1986). İkinci hipotez ise, haksız dağılımların reddedileceğini varsayarak, reddedilme ihtimalinin ortadan kalkması için kişilerin adil dağılımları tercih ettiklerini öne sürer (Güth ve ark., 1982). Çalışma sonuçları bazı aktörlerin tüm parayı kendilerine alırlarken, bazılarının ise parayı ortak şekilde dağıtma eğiliminde olduğunu gösterir (Forsythe, Horowitz, Savin ve Sefton, 1994). Buradan hareketle, insanların sadece bireysel çıkarları gözetmediği, adalet kaygısının da önemli bir rolü olduğu belirtilebilir. Ancak insanların bencillikten tamamen uzak, saf bir adalet duygusuyla davrandığına dair varsayımlar da tartışmalıdır (Bkz. Haselhun ve Mellers, 2005).

Özetle, kişinin karşı taraftan daha fazla veya daha az kaynak aldığı durumlarda ortaya çıkan rahatsızlık, haksızlığın giderilmesi için gerekirse maliyetli bir şekilde kaynak dağılımının reddi ile sonuçlanabilir. Kuramcılar tarafından bu hassasiyet "haksızlıktan kaçınma davranışı” (inequity avoidance) olarak adlandırılmıştır (Fehr ve Schmidt, 1999). Haksızlıktan kaçınma davranışı iki farklı formda ele alınır. Birincisi 'dezavantajl1 haksızlıktan kaçınma' davranışı iken diğeri ‘avantajlı haksızlıktan kaçınma' davranışıdır. Dezavantajlı haksızlıktan kaçınma davranışı, herhangi bir somut gerekçenin olmadı̆̆ı durumlarda dahi, diğerinden daha azına sahip olmaktan kaçınmak olarak tarif edilir. Avantajlı haksızlıktan kaçınma davranışı ise kişınin diğerinden (veya diğerlerinden) daha fazla kaynak almaktan kaçınması olarak tanımlanır (Fehr ve Schmidt, 1999). Avantajlı ve dezavantajlı haksızlıktan kaçınma davranışının iki farklı formda ele alınması, bu davranışın altında yatan farklı sosyal psikolojik mekanizmaların incelenmesine kolaylık sağlar. Her iki haksızlıktan kaçınma formu da iş birliğinin güçlenmesi için gerekli mekanizmalar olarak değerlendirilir (Fehr ve Schmidt, 1999). Bunun yanı sıra, dezavantajlı haksızlıktan kaçınmanın ortaya çıkmasında iki farklı mekanizmanın rol oynadığ1 düşünülür. Birincisi, karşıdakinden daha azına sahip olmanın yarattığı kıskançlık veya öfke gibi olumsuz duygulanımlar, ikincisi ise adalet hassasiyeti olarak belirtilir. Avantajlı haksızlıktan kaçınma davranışında ise adalet hassasiyetinin ve sosyal 
itibar kaygısının önemli rol oynadığı düşünülür. Zira kişi avantajlı olduğu durumu, haksızlığın giderilmesi için feda etmeye gönüllüdür (Blake ve ark., 2015; Fehr ve Schmidt, 1999). Dezavantajlı haksızlıktan kaçınma davranışının yalnızca insanlarda değil diğer bazı primatlarda da olabileceğine işaret eden veriler (Brosnan ve de Waal, 2003; 2014) dezavantajlı haksızlıktan kaçınma davranışının evrimsel bir işlevi olabileceği görüşünü destekler (Bkz. Brosnan, 2006; Van Wolkenten, Brosnan ve de Waal, 2007). Ayrıca gelişimsel incelemelerde de dezavantajlı haksızlıktan kaçınmanın daha erken yaşlarda ortaya çıktığı görülür ve bulgular farklı kültürlerden gelen insanlar için benzer sonuçlar içerir (Blake ve McAullife, 2011; Blake ve ark., 2015). Avantajlı haksızlıktan kaçınma davranışının ise daha ileri yaşlarda ortaya çıktığı ve ortaya çıktığı yaşa dair kültürel farklılıklar barındırdığg görülür (Blake ve ark., 2015). Buradan hareketle, avantajlı haksızlıktan kaçınma daha ileri düzey bir adalet formu olarak nitelendirilir ve ortaya çıkmasında dezavantajlı haksızlıktan kaçınmaya göre sosyalleşme süreçlerinin rolünün daha baskın olduğu düşünülür (Blake ve ark., 2015).

Adalete ilişkin hassasiyetlerin işlevsel bir rolü olduğu açıktır, ancak işlevselliğini anlamak için onun nasıl bir kültürün içinde ve ne zaman ortaya çıktığını anlamak önemlidir. Adalete ilişkin hassasiyetlerin belli formları bazı kültür veya sosyal bağlamlarda davranışa daha erken dökülmektedir (Blake ve ark., 2015). Bunun bir sebebi, bazı bağlam veya kültürlerde diğerlerine göre adalete ilişkin normların gündelik ilişkilerdeki işlevsel rolünün daha baskın olması ve bu sebeple daha erken yaşlarda ortaya çıkması için teşvik edici olması olabilir. Dolayısıyla, mevcut gelişimsel farkların altında yatan faktörlerin ele alınmasında hem ilişkisel hem kültürel hem de bağlamsal olarak adaletin işlevsel rolünü destekleyici unsurları göz önünde bulundurmak akla yatkındır.

\section{Haksızlıktan Kaçınma Davranışına İlişkin Gelişimsel İncelemeler}

Evrimsel temelli görüşler ve ahlaki karar almada sezgisel/otomatik düşünce sisteminin rolünün altını çizen yaklaşımlar, erken çocukluk döneminden itibaren ahlaka ilişkin hassasiyetlerin yeni bir perspektifle incelenmesine kapı aralamaktadır (Haidt ve Bjorklund, 2008). Adaleti evrimsel ve doğuştan gelen (innate) bir mekanizma olarak açıklayan kuramların varsayımlarının test edilmesinde hem diğer primatlarla yapılmış çalışmalar hem de erken dönem çocukluk incelemeleri önem kazanır (Geraci ve Surian, 2011; Ziv ve Sommerville, 2017). Zira bu çalışmalar adaletin bebeklikten başlayarak gelişimsel süreçte nasıl ortaya çıktığını anlamak açısından önemli bilgi sunmaktadır. Böylelikle, hem işbirliğinin evrimine ilişkin açıklamaların test edilmesi mümkün hale 
gelmekte hem de sosyalleşme süreçlerinin rolü gelişimsel bir boyutta daha net şekilde değerlendirilebilmektedir. Bu çalışmalardan birisine göre bebekler henüz dokuz aylık dönemde dahi adalete ilişkin farkındalığa dair emareler göstermektedir; öte yandan 1215 aylık dönemde bebekler için istikrarlı olarak bireysel farklılıkların önemi artmaktadır (Ziv ve Sommerville, 2017). Başka çalışmalarda 15 aylık bebekler için yalnızca adalete dayalı seçimlerin değil, ırkın da önemli bir tercih unsuru olabileceği görülmektedir (Burns ve Sommerville, 2014). Daha detaylica belirtmek gerekirse, beyaz bebekler her iki alıcının da beyaz yetişkinler olduğu durumda adil dağıtıcıyı daha fazla tercih etmektedir. Ancak bu tercih adil dağıtım yapan aktörün Asyalı olduğu, adaletsiz dağıtım yapan aktörün ise beyaz olduğu durumda ortaya çıkmamaktadır. Aynı çalışmada gerçekleştirilen ikinci bir deneyde ise bebekler Asyalı aktöre avantaj sağlayan haksız dağıtıcıyı anlamlı olarak daha az tercih etmektedirler ${ }^{2}$. Dolayısıyla giderek artan sayıda inceleme sonuçları, insanların henüz bebeklik döneminde dahi adalete ilişkin farkındalığga sahip olduğunu göstererek adaletin işbirliğinin sağlanmasında evrimsel rolü olduğu görüşünü desteklemektedir (DesChamps, Eason ve Sommerville, 2015; Meristo, Strid ve Surian, 2015; Lucca, Pospisil ve Sommerville, 2018).

Bebeklerin yetişkinlerle ve kendilerinden büyük kardeşleriyle girdikleri etkileşimlerin içeriği, sıklığı ve aile üyelerinin adalete ilişkin öğretileri, bebeklikte adalete ilişkin beklentilerin ortaya çıktığg dönemi etkiliyor olabilir (Ziv ve Sommerville, 2017). Bu konu üzerine yapılacak kültürlerarası çalışmalar, Sommerville ve Ziv’in (2018) de önerdikleri gibi, adalete ilişkin hassasiyetlerin başlangıç yaşını anlamada sosyalleşme süreçlerinin rolünü ortaya serecektir. Zira farklı kültürlerde adalete ilişkin hassasiyetler benzer gelişimsel dönemlerde ortaya çıkıyorsa, adaletin evrimsel ve doğuştan gelen bir mekanizma olduğu argümanı güçlenecektir. Ancak ilgili çalışmaların büyük kısmındaki veriler Batılı örneklemlerden gelmektedir (DesChamps ve ark., 2015; Lucca ve ark., 2018; Meristo ve ark., 2015; Ziv ve Sommerville, 2017). Tahmin edilebileceği gibi bu durum, bebeklik döneminde adalete ilişkin hassasiyetlerin ortaya çıkması için (varsa) önemli olabilecek (kültüre özgü) sosyalleşme faktörlerinin etkisine ilişkin yorumlamalar yapmaya engel olmaktadır.

Adil dağılım beklentileri erken yaş dönemlerinde gözlense bile, bu beklentilerin paralelinde adil davranışın gerçekleşmesi (tahmin edilebileceği gibi) daha geç yaşlarda

2 Bu araştırmanın (Burns ve Sommerville, 2014) sonuçları iç gruba dair yanlılıkların bebeklik döneminde de kendini gösteriyor olabileceğine işaret eden bulguları destekler niteliktedir. Örneğin, Jin ve Baillargeon (2017) yaptıkları incelemenin sonucunda 17 aylık bebeklerde iç grup yanlılığına ilişkin emareler olduğunu belirtmektedir. 
ortaya çıkmaktadır. Zira adalete ilişkin farkındalık, adil seçimlerin veya davranışların sergilenmesi için gerekli olan bilişsel ve sosyal repertuvarın yalnızca bir kısmıdır. Örneğin üç yaş döneminde çocuklar eşitlikçi prensipleri desteklediklerini belirtirlerken (Smith, Blake ve Harris, 2013), çocukların eşitlikçi tercihler üzerinden kaynak dağıl1mında bulunması okul öncesi dönemde nadiren görülmektedir (Bkz. Benenson, Pascoe ve Radmore, 2007; Malti, Gummerum, Keller, Chaparro ve Buchmann, 2012). İncelemelerde üç yaşındaki çocukların diğerinden daha az kaynak aldıkları durumlarda mutsuzluk belirtileri sergiledikleri (LoBue ve ark., 2011) ve dört yaşındaki çocukların dezavantajlı haksızlıktan kaçınmak için kaynakları feda etme eğiliminde oldukları görülmektedir (Blake ve McAuliffe, 2011; McAuliffe, Blake, Kim, Wrangham ve Warneken, 2013). Çalışmaların bazıları dezavantajlı haksızlıktan kaçınmanın 4-5 yaş civarında ortaya çıktığını göstermektedir (Blake ve McAuliffe, 2011; Takagishi, Kameshima, Schug, Koizumi ve Yamagishi, 2010), ancak bu yaş döneminde çocukların yapılan dağılımların adil olup olmadığına bakmaksızın tümünü kabul ettiklerini gösteren bulgular da mevcuttur. Örneğin Bereby-Meyer ve Fiks (2013) dağılımlarda beş yaşındaki çocukların yalnızca kendi kazançlarına odaklandıklarını ve adalete ilişkin normları henüz anlayamadıklarını belirtmektedir. Öte yandan Baumard, Mascaro ve Chevallier (2012) henüz 3-4 yaşındaki çocukların, üçüncü bir kişi olarak dağıtım yaparken liyakate dayalı tercihlerde bulunduklarını bulmuşlardır (Bkz. Li, Spitzer ve Olson, 2014). Erken yaş dönemlerinde (4-5 yaş) çocuklar kendi yaptıkları dağılımlarda, kendileri için maliyeti olsa bile yabancılara kıyasla arkadaşlarına yönelik daha eşitlikçi kaynak dağılımları yapmaktadır (Moore, 2009). Dolayısıyla paylaşımın kiminle yapıldığı da bu dönemde önem kazanmaktadır (Bkz. Fehr, Bernhard ve Rockenbach, 2008).

Damon (1975) benzer şekilde adalete ilişkin hassasiyetlerin emarelerini erken çocukluk döneminde gösterdiğini belirtmekle beraber, henüz dört yaşındaki çocukların oldukça bencil şekilde kendi arzu ve dileklerine dayalı tercihlerde bulunurlarken, beş yaşında katı bir eşitlikçi tutum sergileme eğiliminde olduklarını ve ancak altı yaşından itibaren liyakate dayalı akıl yürütebildiklerini öne sürmektedir (Bkz. Lane ve Coon, 1972; Nisan, 1984). Ancak çalışma bulgularından anlaşılabileceği gibi daha güncel veriler varsayılandan çok daha erken dönemlerde dahi adalet beklentisinin gözlenebilir olduğuna işaret etmektedir. Öte yandan çocukların kendi avantajlı bulundukları durumlardan kaçınma davranışını sergilemeleri (bekleneceği üzere) daha geç yaşlarda ortaya çıkmaktadır. Diğer bir deyişle, bebekler ve çocuklar adil olan ve olmayan ayrımı- 
nı doğru yapabilmekte fakat kendi avantajlı oldukları adaletsiz durumlara karşı çıkmamaktadır. Avantajlı haksızlıktan kaçınmanın erken çocukluk döneminde incelendiği ilk çalışmalardan birisi Lobue ve arkadaşları (2011) tarafından gerçekleştirilmiştir. Bu çalışmada dört yaşında iki kız çocuğunun partnerlerinden daha fazla kaynak almaya doğrudan itiraz ettikleri ve kaynak dağılımında avantajlı olan beş çocuğun dört çıkartmadan bir tanesini, partnerleri böyle bir talepte bulunmadan onlara verdikleri gözlemlenmiştir. İlgili çalışmalardan bir diğerinde Fehr ve arkadaşları (2008), 3-4 yaş grubundaki çocukların bencil tercihlerde bulunduklarını, 5-6 ve 7-8 yaş grubundaki çocukların giderek daha eşitlikçi tercihlere yöneldiklerini bulmuşlardır. Benzer şekilde, Shaw ve Olson'un (2012) çalışma sonuçlarına göre, çocuklar bu yaş döneminde avantajlı oldukları durumlardan eşitliğin sağlanması için feragat etmektedirler. Blake ve McAuliffe (2011) ise yaptıkları incelemede hem dezavantajlı hem avantajlı haksızlık oyununu inceleyebilecekleri güncel bir ekonomi oyunu kullanmışlardır. 'Haksızlık Oyunu' ismini verdikleri bu oyunda, Ültimatom ve Diktatör oyunundan farklı olarak, kaynak dağılımı üçüncü bir kişi tarafından gerçekleştirilmektedir. Haksızlık Oyununun kullanıldığg ilk inceleme sonuçları, 4-7 yaş arasındaki çocukların dezavantajlı oldukları dağılım tekliflerini reddedip, avantajlı oldukları dağılımları kabul ettiklerini göstermektedir (Bkz. Acun ve Karakelle, 2019; Benenson ve ark., 2007; Blake ve Rand, 2010; Gummerum, Hanoch, Keller, Parsons ve Hummel, 2010). Buna karşın, sonuçlara göre sekiz yaşındaki çocuklar ise hem avantajlı hem dezavantajlı oldukları durumlarda her iki eşitsizlik formunu da reddederek eşitlik için kaynakları feda etmektedirler (Blake ve McAuliffe, 2011).

Çocukların yaşı büyüdükçe adil tercihlerinde giderek artış olduğu görülmektedir (McAuliffe, Blake, Steinbeis ve Warneken, 2017). Örneğin, 7-8 yaşındaki çocuklar daha erken yaşlara göre daha paylaşımcı olmaktadır (Bkz. Fehr ve ark., 2008; Rochat ve ark., 2009; Shaw, Choshen-Hillel ve Caruso, 2016). Ancak bu durum adalete ilişkin hassasiyetlerinden kaynaklı gerçekleşebileceği gibi çocukların kullandıkları stratejilerin zenginleşmesiyle ilişkili olarak da yorumlanmaktadır. Harbaugh, Krause ve Liday (2003) küçük çocukların 'Ültimatom Oyunu'nda sunulan düşük miktarları daha fazla kabul ettiklerini belirtmektedirler. Rizzo ve Killen (2016) ise çocukların kaynak dağılımlarına ilişkin değerlendirmelerinde 3-4 yaş grubunun eşitliğe yönelik dağılımları tercih ettiklerini bulmuşlardır. Sonuçlar, 5-6 yaş grubundaki çocukların liyakate dayalı ve eşit dağılımlar arasındaki değerlendirmelerini benzer şekilde adil olarak yorumladıklarını, 7-8 yaş grubundaki çocukların ise liyakate dayalı tercihleri eşit tercihlerden daha pozitif 
değerlendirdiklerini göstermiştir. Buna göre, çocuklar yaşları arttıkça eşitlikçi ve liyakate dayalı dağılımları daha doğru şekilde ayırabilmektedirler. Güroğlu, van den Bos ve Crone (2009) da farklı yaş gruplarındaki çocukların ekonomi oyunlarında farklı stratejilerle ilerlediklerini belirtmektedirler. Çocukların 9-18 yaş arasında alıcının dağılımı reddedemediği durumlarda benzer oranlarda kaynak önerdikleri, alıcının kaynağı reddetme ihtimalinin olduğu durumda ise, yaş arttıkça kaynak dağılımında daha adil bir örüntü sergiledikleri görülmektedir. ${ }^{3}$

Bu noktada özel olarak belirtmek gerekir ki, bu çalışma sonuçlarının büyük bölümü ABD'de yaşayan çocukların katılımcı olduğu incelemelerden gelmektedir (Örn., Blake ve McAuliffe, 2011; Blake ve Rand, 2010; Damon, 1975; Harbaugh ve ark., 2003; Li, Spitzer ve Olson, 2014; LoBue ve ark., 2011; McAuliffe ve ark., 2013; Nisan, 1984; Smith ve ark., 2013; Rizzo ve Killen, 2016; Shaw ve ark., 2016). Öte yandan, ABD d1Şından alınan verilerin büyük kısmı da bireysel değerlerin baskın olduğu kültürlerde yaşayan çocuklardan alınmıştır (Benenson ve ark., 2007; Fehr ve ark., 2008; Gummerum ve ark., 2010; Malti ve ark., 2012). Dolayısıyla, ortaya çıkan sonuçları açıklamak üzere öne sürülen hipotezlerin kültürel bir yanlılık içerip içermediğinden emin olmak için, benzer hipotezlerin Batılı olmayan kültürlerden alınan verilerle test edilmesi gerektiği açıktır.

\section{Haksızlıktan Kaçınma Davranışının Ortaya Çıkmasında Sosyal Bağlam ve İtibar Kaygisının Rolü}

Haksızlıktan kaçınma davranışını sergilemenin neden ortaya çıktığı sorusuna genel olarak iki ayrı hipotezle yanıt aranmaktadır. Sosyal hipoteze göre, haksızlıktan kaçınma davranışı işbirliği sonucunda elde edilmiş kaynakların paylaşımında bireylerin katkısının sömürülmesini engellemek için gelişmiştir. Bir diğer hipotez ise haksızlıktan kaçınmanın, beklenen getiri ve elde edilen getirinin hesaplanmasında rol oynayan daha genel bir mekanizmanın, diğer bir deyişle alana genel bir tepkinin sonucu olarak ortaya çıktığını ileri sürmektedir (Hamann, Bender ve Tomasello, 2014). Bu iki farklı hipotezi tek bir çalışmada ele alan McAullife ve arkadaşları (2013) çocukların gerçek bir partnerinin olduğu ve bir partnerinin olmadığı durumları karşılaştırmışlardır. Sonuçlara göre dezavantajlı eşitsizlik koşulunda, tüm yaş gruplarındaki çocuklar eşitsiz dağılımı sosyal ol-

3 Çocukların yaşla beraber zihin kuramı (Castelli, Massaro, Sanfey ve Marchetti, 2014; Takagishi ve ark., 2010) ve ketleyici kontrol becerilerinin gelişmesinin (Xie, Pei ve Su, 2019) adalete ilişskin davranışların sergilenmesinde önemli olabileceğini gösteren veriler mevcuttur. 
mayan versiyondan daha sik reddetmekte, ancak yine de dezavantajlı haksızlıktan kaçınma davranışını partnerlerinin olmadığı durumda dahi sergilemektedirler. Avantajlı haksızlık durumunda, sekiz ve dokuz yaşındaki çocuklar partnerlerinin bulunduğu durumda avantajlı oldukları haksız teklifleri (örn., bir oyuncuya 4 adet, diğer oyuncuya 1 adet kaynak sunmak gibi) partnerin olmadığı oyuna göre anlamlı olarak daha fazla reddetmektedir. Bu sonuçları yorumlarken her iki hipotezin de haksızlıktan kaçınma davranışı için açıklayıcı rolü olabileceğinin altını çizen araştırmacılar, insanların haksızlıkla karşılaştıklarında alana genel bir mekanizmayla tepki gösterdiklerini, ancak bu davranıŞın sosyal bağlamın gerekliliklerine paralel olarak zenginleşiyor olabileceğini belirtmektedir. Bununla birlikte, sosyal hipotezi test etmenin bir diğer yöntemi, işbirliğinin sonucunda kazanılan kaynağın adil dağılımlarda artış yaratıp yaratmadığını incelemektir (Blake, McAuliffe ve Warneken, 2014). Çalışmalar sosyal hipotezin varsayımına paralel olarak, erken çocukluk döneminde dahi ortaklaşa iş yapmanın adil dağılımları artırdığını göstermektedir (Hamann, Bender ve Tomasello, 2014; Hamann, Warneken, Greenberg ve Tomasello, 2011).

$\mathrm{Bu}$ durumda akla çocukların neden dezavantajlı oldukları haksız tercihlerden kaçınırlarken, eşit tercihlere daha fazla yöneldikleri sorusu gelmektedir. Buna ilişkin açıklamalardan birisi, bu yönelimin erken yaşlarda çocukların diğerinden daha az almalarından ötürü yaşadıkları hayal kırıklığından dolayı ortaya çıktığını öne sürerken, diğeri ise çocukların dezavantajlı haksızlıkla karşılaştıklarında ortaya çıkan hınç duygusundan dolay1 dağılımı reddettiklerini öne sürmektedir (Blake ve McAuliffe, 2011). McAuliffe, Blake ve Warneken'in (2014) bu iki hipotezi karşılaştırmak için gerçekleştirdikleri çalışmada, çocukların diğerinden daha az paya sahip olsalar bile, partnerleri onların tercihinden bağımsız olarak zaten daha fazla kaynak aldıklarında deney yürütücüsü tarafından onlara sunulan kaynağı kabul ettikleri görülmektedir. Öte yandan partnerlerinin de kaynak almasına engel olabilecekleri koşulda, dağılımı reddetmeyi tercih etmektedirler. $\mathrm{Bu}$ durum erken çocukluk döneminde dezavantajlı haksızlıktan kaçınmanın hayal kırıklığından ziyade kindarlıkla ilişkili olabileceği yorumunu güçlendirmektedir. Öte taraftan, gelişimin erken dönemlerinde çocukların eşitlikçi duygularla dezavantajlı haksızlıktan kaçınıyor oldukları argümanını da zayıflatmaktadır"

4 Aynı çalışmada (McAuliffe, Blake ve Warneken, 2014) yetişkinlerin çocuklardan farklı olarak dezavantajlı haksızlık koşulunu daha fazla kabul ederken, avantajlı haksızlık durumlarını daha fazla reddettikleri bulunmuştur. Yüz yüze oynanan ekonomi oyunlarında yetişkinler için itibara ilişkin kaygıların devreye giriyor olması bu sonuçları açıklıyor olabilir. 
Blake ve McAuliffe'in (2011) çalışması, haksızlıktan kaçınmaya dair bu iki farklı mekanizmanın gelişimsel olarak farklı süreçlere tekabül ettiğini gösterir. Daha önce de bahsedildiği gibi, avantajlı haksızlıktan kaçınma davranışının sekiz yaş döneminde ortaya çıkması, çocuklar için sosyal itibarın daha fazla önem kazandığı bir dönem olmasıyla ilişkili olabilir. Bir başka açıklama ise bu dönemde çocukların, adalete ilişkin hassasiyetleri içselleştirmeye başlıyor olabileceği yönündedir (Tomasello, 2018). Bunun yanı sıra, iki açıklamadan birinin diğerinden bağımsız olarak haksızlıktan kaçınma davranışı üzerinde etkili olduğunu öne sürmek yerine, iki farklı açıklamanın da varsayımlarının eş zamanlı olarak geçerli olacağı düşünülebilir. Zira Tomasello'nun (2018) da belirttiği gibi her iki açıklama da çocukların bu dönemde sosyal beklentilerin eşitlikçi normlara dayandığını fark ettiklerine işaret eder. Ancak her kültürde adalete ilişkin beklentiler eşitlikçi normlara dayanmayabilir. Dolayısıyla avantajlı haksızlıktan kaçınma davranışının eşitlikçi normların baskın olduğu kültürlerde daha erken görülmesini beklemek yanlış olmayacaktır. Ancak daha önce de değinildiği gibi, bu varsayımı test etmek için kültürlerarası karşılaştırmalar yapan kısıtlı sayıda inceleme vardır (Blake ve ark., 2015; Rochat ve ark., 2009).

\section{Kültürün Haksızlıktan Kaçınma Davranışının Ortaya Çıktığı Yaş Üzerindeki Rolü}

Blake ve arkadaşları (2015) yedi farklı ülkede gerçekleştirdikleri çalışmalarda haksızlıktan kaçınma davranışının ortaya çıktığı yaşların kültürden kültüre farklılık taşıdığını gösterdiler. Sonuçlara göre avantajlı haksızlıktan kaçınma davranışı ABD, Kanada ve Uganda'da geç çocukluk döneminde ortaya çıkmaktadır. Öte yandan, Hindistan, Meksika, Peru ve Senegal' de yaşayan çocuklar avantajlı haksızlık durumlarını eşitlikçi durumlardan anlamlı olarak daha fazla reddetmemektedirler. Dezavantajlı haksızlık durumlarında ise veri alınan tüm ülkelerde çocuklar dağılımı reddetmeyi anlamlı olarak daha fazla tercih etmişlerdir. Bu durum, dezavantajlı haksızlıktan kaçınmanın evrensel olduğu ve işbirliğinin güçlenmesi için önemli evrimsel köklere dayandığı varsayımını güçlendirmektedir (Brosnan ve de Waal, 2012; 2014). Öte yandan avantajlı haksızlıktan kaçınma davranışı ise çocukların içinde yaşadığı kültürel normlara ve sosyalleşme pratiklerine karşı daha hassas gözükmektedir.

Batılı toplumlarda eşitlikçi normların Batılı olmayan toplumlara nazaran daha fazla cesaretlendirilmesi çocukların haksızlıktan kaçınma davranışının gelişiminde ortaya çıkan kültürlerarası farklılığı açıklamada önemli bir unsur olarak görülebilir. ABD ve Kanada'da yaşayan çocukların daha erken yaşlarda avantajlı haksızlıktan kaçınma 
davranışı sergilemesi eşitlikçiliğin cesaretlendirildiği bir çevrede yetiştirilmeleriyle ilgili olabilir(Blake ve ark., 2015) ${ }^{5}$. Yedi farklı ülkede üç ve beş yaş arasındaki çocukların kaynak dağılımlarının incelendiği bir başka çalışmada ise, çocukların kültürden bağımsız olarak alıcı oldukları haksız dağılım durumlarında kendi çıkarlarını gözeterek tercihte bulundukları görülmüştür (Rochat ve ark., 2009). Ancak çocukların çıkara dayalı tercihleri, beklendiği üzere yaşla beraber giderek azalmıştır. Kolektivist kültüre sahip Peru ve Fiji'den alınan verilerde, çocukların kendilerine daha az şeker ayırarak dağılım yaptıkları ve daha cömert oldukları bulunmuştur. Araştırmacılar Peru ve Fiji'deki katılımcıların yaşadığı bölgede, kişilerin geniş aile düzeninin yaygın olduğu kırsal kesimlerde yaşadıklarını ve yaygın olarak toplu aktivitelerde bulunduklarını belirtmektedirler. Dolayısıyla, daha cömert kaynak dağılımları, çocukların yaşadıkları bölgenin ve hayat tarzlarının getirisi olabilir. Zira kırsal bölgeler, kentsel bölgelere nazaran bireysel başarının daha az önemli olduğu ve daha az rekabetçi bir hayat tarzı içermektedir. Bu çalışma sonuçlarından hareketle haksızlıktan kaçınma için çocukların gündelik hayatta içinde bulunduğu yaşam tarzı ve deneyimlerin önemli olduğu görülmektedir. Daha güncel bir çalışmada da belirli sosyal faktörlerin adalete ilişkin tercihlerdeki rolünü anlamak hedeflenmiştir (Kajanus, McAuliffe, Warneken ve Blake, 2019). Bunun için farklı eğitim sistemlerinden geçen ve niteliksel olarak farklı sosyalleşme pratiklerine maruz kalan 8-9 yaşlarındaki Çinli öğrencilerin avantajlı ve dezavantajlı haksızlıktan kaçınma davranışları incelenmiştir (Kajanus ve ark., 2019). Sonuç olarak, beklenenin aksine iki ayrı okulda öğrenim gören çocuklar benzer şekilde hem dezavantajı hem avantajlı oldukları dağılımları reddetmişlerdir 6 . Bu inceleme sonuçları sosyalleşme pratiklerinin adaletsizlikten kaçınmanın ortaya çıkmasında farklılık yaratabileceği argümanını zayıflatmaktadır. Paulus (2015) Batılı olmayan bir kültürden (Uganda) aldığı verilere dayanarak, çocukların evrensel olarak eşitlikçiliğe dair güçlü tercihleri olmayabileceğini ifade etmektedir. Shaw ve Olson (2012) tarafından yürütülen benzer bir araştırmanın replikasyonu olan bu inceleme, ABD'de toplanan verilerden farklı bir sonuç ortaya koymaktadır. Sonuçlara göre, Uganda'da yapılan incelemede (Paulus, 2015) çocuklar eşitsizlikle sonuçlanacak olsa bile fazladan kaynağın çöpe atılmasını değil, bir kişiye

5 Araştırmacılar bu incelemede (Blake, ve ark., 2015) bulguları yorumlarken Uganda'da çalışmaya katılan çocukların eğitim aldıkları kurumda Batılı öğretmenlerle etkileşim halinde olduklarını ve adalete ilişkin Batılı normların model alınmış olabileceğini belirtmektedirler.

6 Ancak bu çalışmada (Kajanus ve ark., 2019), deney öncesi pratik denemelerinde okul türünün çocukların avantajlı haksızlıktan kaçınma davranışlarında fark yarattığg görülmüştür. Bu fark, deney esnasında alınan verilerde bulunmamıştır. 
verilmesini anlamlı olarak daha fazla tercih etmektedir. Bu iki benzer araştırmanın fark11 yönde sonuçlar doğurması kültürün ve ekonomik koşulların göz önünde bulundurulmasının önemini akla getirmektedir. Shaw ve Olson'nun (2012) incelemesinde katılımcılar ABD’nin refah düzeyi yüksek bir kesiminde yer alan çocuklardan oluşmaktadır. Oysa Paulus (2015) refah düzeyi yüksek olmayan (çoğunluğu işçi aileden gelen) bir gruptan veri topladığını belirtir. Bu nedenle çocuklar deney esnasında kaynağın çöpe atılmasındansa bir kişiye verilmesini ziyandan kaçınma kaygısıyla tercih etmiş olabilirler. ABD’den alınan örneklemdeki çocuklar ise refah düzeyi yüksek bir kesimi temsil ettiğinden böyle bir kaygı gütmek yerine, eşitlikçi normların arzulanmasını ön plana çıkarmış olabilirler. Türkiye'de yapılan daha güncel bir çalışmada (Acun ve Karakelle, 2019) beş yaşındaki çocukların avantajlı oldukları dağılımı daha fazla reddettikleri bulunmuştur. Öte yandan, bu çalışmada çocukların ortaklaşa iş yapmasının eşitsizlikten kaçınmada bir etkisi olmadığı görülmüştür. Bu bulgular, hem ortaklaşa iş yapmanın eşitlikçi tercihleri güçlendirdiğini gösteren (Corbit, McAuliffe, Callaghan, Blake ve Warneken, 2017; Hamann ve ark., 2011; 2014) hem de çocukların sekiz yaşından önce avantajlı bulundukları haksızlık durumlarını reddetme eğiliminde olmadığını gösteren (Blake ve McAullife, 2011) çalışma bulgularına ters düşmektedir. Türkiye'den alınan verilerde çocukların kendi avantajlı oldukları durumları anlamlı ölçüde reddetmesi kültürel çıkarımlarla yorumlamaya açıktır. Örneğin, Türkiyeli çocuklar ilişkilerin korunmasına verdikleri önemden dolayı oyundaki partnerlerinin kendilerine yönelik bakış açısına daha fazla odaklanmış ve olumsuz bir değerlendirmeden kaçınmayı amaçlamış olabilirler. Öte yandan, Blake ve arkadaşları (2015), çalışma sonuçlarını yorumlarken, toplulukçu kültürlerde eşitlikçi normların daha az cesaretlendiriliyor olabileceğine işaret etmektedir. Ancak haksızlıktan kaçınmanın daha üst bir formu olarak değerlendirilen avantajlı haksızlıktan kaçınma (McAuliffe ve ark., 2017) Türkiye ve Çin gibi toplulukçu olarak değerlendirilebilecek kültürlerde de (İmamoğlu, 1987; Kağıtçıbaşı, 2012) ABD ve Kanada'ya benzer şekilde çocukluk döneminde ortaya çıkmaktadır (Bkz. Acun ve Karakelle, 2019; Kajanus ve ark., 2019). Bu durumda, toplulukçu değerler avantajlı oldukları durumda çocukların kendi kaynaklarından eşitliği sağlamak için feragat ettiklerini göstermektedir.

Özetle, tüm bu bulgular değerlendirildiğinde, ortaya çıkan tablo tutarlı değildir. Dolayısıyla kültürlenmenin ve ekonomik koşulların bu konu üzerindeki etkilerini tartışmak için farklı örneklemlerden daha fazla bilgiye ihtiyaç olduğu açıktır. Sonuç olarak, Batılı 
ya da Batılı olmayan veya bireyselci ya da toplulukçu ayrımı üzerinden adalete ilişkin hassasiyetleri anlamaya çalışmak yeterince açıklayıcı ve işlevsel gözükmemektedir. Bunun yerine, örneklem alınan yerleşim yerinin özellikleri, ekonomik koşullar, ailevi değerler ve sosyalleşme pratiklerinin mercek altına alındığı çalışmalar ortaya çıkan farklılıklarda açıklayııı bir rol oynayabilir.

\section{TARTIŞMA}

Adalet kavramının gelişimsel olarak ele alındığı bu derleme çalışmasında sunulan incelemelere göre, bebekler dahi adil olan ve olmayan arasındaki farkı ayırt edebilir (Ziv ve Sommerville, 2017) ve çocuklar, erken yaştan itibaren haksılılıtan bedel ödeyerek kaçınabilirler (Blake ve McAuliffe, 2011). Bu bulgular, bir bütün olarak değerlendirildiğinde, ahlaka ilişkin sosyal sezgiselci yaklaşımları ve adaletin evrimsel kökenlerine ilişkin varsayımları desteklemektedir (Curry, 2016; Haidt, 2001). Gelişimsel bir boyut üzerinde değerlendirildiğinde, dezavantajlı haksızlıktan kaçınma davranışı, avantajlı haksızlıktan kaçınma davranışına göre daha erken yaşta ortaya çıkmaktadır (Blake, McAuliffe ve Warneken, 2014). Bu noktada, dezavantajlı haksızlıktan kaçınmanın daha erken yaşta ortaya çıkması ve birçok farklı kültürde sonuçların tekrar edilmesi, dezavantajlı haksızlıktan kaçınmanın işbirliğinin evriminde önemli bir rol oynadığı argümanını güçlendirmektedir (Blake ve McAuliffe, 2011; Blake ve ark., 2015; Brosnan ve de Waal, 2003; Fletcher, 2008). Öte yandan avantajlı haksızlıktan kaçınma davranışının ortaya çıktığı yaş dönemine ilişkin bulgular kültürel farklılıklara daha açıktır. Buradan hareketle, bulgular, avantajı haksızlıktan kaçınma davranışının ortaya çıkmasında sosyal faktörlerin rolüne odaklanmanın önemine işaret etmektedir.

Bir bütün olarak değerlendirildiğinde, mevcut incelemelerde ortaya çıkan kültürel farklılıkları toplulukçu ve bireyselci ikili sınıflandırması üzerinden ele alarak açıklamaya çalışmak, avantajlı haksızlıktan kaçınmanın gelişimsel olarak ortaya çııtığı yaşın hangi sosyal motivasyonlardan destek aldığını anlamak için yeterli gözükmemektedir. Örneğin, Uganda, Türkiye ve Çin gibi kültürler toplulukçu değerlerin baskın olduğu kültürlere örnek olarak verilebilir. Bu ülkelerde yaşayan çocuklar bireyselci olarak değerlendirebileceğimiz kültürlerden (ABD ve İngiltere gibi) alınan verilere benzer şekilde, avantajlı oldukları haksızlık durumlarını reddetme eğilimi sergilemektedir (Acun ve Karakelle, 2019; Kajanus ve ark., 2019; Paulus, 2015; Shaw ve Olson, 2012). Dolay1sıyla bireyselci ve toplulukçu eksende açıklamalar yapmak yeterli gözükmemektedir. 
Diğer bir deyişle, özel olarak avantajlı haksızlıktan kaçınma davranışının sergilenmesinde ortaya çıkan gelişimsel farklar ve bu farkların altında yatan sosyalleşme süreçlerinin neler olduğu hala netliğe kavuşmamıştır.

$\mathrm{Bu}$ belirsizliğin sebeplerinden birisi Batı dışındaki örneklemlerle yapılmış oldukça az sayıda inceleme olmasıdır. Bununla birlikte, adalete ilişkin gelişimsel ve kültürlerarası karşılaştırmalarda gündelik hayata ilişkin pratikler, ana-baba tutumları ve kültürel değerlere ilişkin ölçümler araştırmalar içerisinde bilindiği kadarıyla detaylıca ele alınmamıştır. Oysa bu bilgilerin edinilmesi mevcut bulguların kültürel farklar açısından yorumlanmasını kolaylaştıracaktır. Örneğin, ortaya çıkan kültürel farklılıkları daha iyi anlamak için farklı yaşam şekillerine ve kaynak dağılımında beklentilerin farklılaşmasına odaklanmak yardımcı olabilir. Rai ve Fiske'nin (2011), farklı sosyal durumlarda belirli ilişki modellerinin daha fazla ön plana çıkabileceğine işaret eden ve sosyal bağlama vurgu yapan ilişki modelleri kuramının temel varsayımları, adalet hassasiyetinin gelişimine dair çalışmalar için de önemlidir. Rai ve Fiske (2011), öne sürdükleri modelde, sosyal ilişkilerin düzenlenmesi için eşitlik temelli bir anlayışın bazı bağlamlarda işlevsel bir motivasyon olarak karşımıza çıkabildiğini, ancak bazı bağlamlarda ise emek ve kazanç oranı gözetilerek karar almanın daha geçerli görülebildiğini belirtmektedirler. Yalnızca anlık bağlamsal değişiklikler değil, kültüre özgü farklılıklar da belli ilişki modellerini ve buna bağlı ahlaki motivasyonları diğerlerine göre ön planda tutmaya zemin hazırlıyor olabilir. Örneğin, Tepe ve Aydınlı-Karakulak (2019) Amerikalı katılımcıların Türkiye'deki katılımcılara göre eşitlik motivasyonuna, Türkiye'deki katılımcıların ise birlik motivasyonuna daha fazla başvurduğunu bulmuştur. Bu noktada, mevcut bulguları yorumlama konusunda bireyselci ve toplulukçu ikili sınıflandırması yerine, Kağıtçıbaşı'nın (2012) modelini kullanmak daha açıklayıcı olabilir. Kağıtçıbaşı'nın (2012) 'benlik' kavramının inşasında kültürel farklılıkların belirleyici olduğuna dayanan açıklamasına dayanarak, ben’i diğerleriyle doğrudan ilişki içerisinde kavrayan toplumlar için, adaletin davranışsal boyutunun bir norm olarak ortaya çıkması beklenebilir. Böyle bir durumda bir başkası için adil olduğuna inanılan bir karar almak gayet tabii karşılanırken; ben'i diğerlerinden ayrı kavrayan toplumlarda adaletin davranışsal boyuta yansıması, diğerinin özgürlüğüne ve hayatına müdahale olarak kavranabilir. Buradan yola çıkarak, kültürler arası adalet çalışmalarının en başta bir etnosentrizm sorunuyla karşılaştığı ve bu sorunun açıklığa kavuşturulması gerektiği söylenebilir. Diğer yandan, bu çalışmalar sadece davranışsal boyutu gözlemlememize yardımcı olurken, altında yatan 
hassasiyetin hangi temellere dayandığına dair kesin bulgular sunamamaktadır. Bu sebeple, yalnızca mevcut bulgulara dayanarak toplumları toplulukçu ve bireyselci olarak genel bir sınıflandırmaya tabi tutmanın da tartışmalı olduğunu iddia etmek mümkün gözükmektedir (Kağıtçıbaşı, 2012).

Bunlara ek olarak, ilgili incelemeler yapılırken gözetilebilecek bir başka önemli unsur üretim ilişkileri, ekonomik sistem ve maddi imkanlar olabilir. Batılı sanayi topluluklarında eşitlikçi yaklaşımlar cesaretlendirilirken, üretim ve tüketim ilişkilerinin daha küçük ölçekte gerçekleştiği topluluklarda eşitsizlikler daha az önemseniyor olabilir. Birilerinin diğerinden daha fazla paya sahip olmasının yarattığı rahatsızlığın yaşam şekillerinden, ekonomik sistemden ve maddi olanaklardan etkilenmesi olasıdır.

Buradan hareketle, gelecek çalışmaların, yaygın sosyalleşme pratiklerini göz önünde bulunduran, sosyal bağlamın rolünü ön plana çıkarmayı amaçlayan (Rai ve Fiske, 2011) ve bireylerarası ilişki dinamiklerini açıklamalarında es geçmeyen (Kağıtçıbaşı, 2012) bir bakış açısıyla gerçekleştirilmesi ilgili alana önemli ölçüde katkı sunacaktır.

\footnotetext{
Hakem Değerlendirmesi: Dış bağımsız.

Çıkar Çatışması: Yazar çıkar çatışması bildirmemiştir.

Finansal Destek: Yazar bu çalışma için finansal destek almadığını beyan etmiştir.
}

Peer-review: Externally peer-reviewed.

Conflict of Interest: The author has no conflict of interest to declare.

Grant Support: The author declared that this study has received no financial support.

\section{Kaynakça/References}

Acun, E. ve Karakelle, S. (2019). 4-6 yaş çocuklarında kaynak dağıtımında eşitsizlikten kaçınmayı etkileyen faktörlerin incelenmesi. Psikoloji Çalışmalarl, 39(1), 99-119. DOI: 10.26650/SP20180034

Baumard, N., Mascaro, O. ve Chevallier, C. (2012). Preschoolers are able to take merit into account when distributing goods. Developmental Psychology, 48(2), 492- 498. https://doi.org/10.1037/ a0026598

Benenson, J. F., Pascoe, J. ve Radmore, N. (2007). Children's altruistic behavior in the dictator game. Evolution and Human Behavior, 28(3), 168-175. https://doi.org/10.1016/j. evolhumbehav.2006.10.003

Bereby-Meyer, Y. ve Fiks, S. (2013). Changes in negative reciprocity as a function of age. Journal of Behavioral Decision Making, 26(4), 397-403. https://doi.org/10.1002/bdm.1768

Blake, P. R. ve McAuliffe, K. (2011). "I had so much it didn't seem fair”: Eight-year-olds reject two forms of inequity. Cognition, 120(2), 215-224. https://doi.org/10.1016/j.cognition.2011.04.006 
Blake, P. R. ve Rand, D. G. (2010). Currency value moderates equity preference among young children. Evolution and Human Behavior, 31(3), 210-218. https://doi.org/10.1016/j. evolhumbehav.2009.06.012

Blake, P. R., McAuliffe, K., Corbit, J., Callaghan, T. C., Barry, O., Bowie, A., ... ve Wrangham, R. (2015). The ontogeny of fairness in seven societies. Nature, 528(7581), 258-261. https://doi. org/10.1038/nature 15703

Blake, P. R., McAuliffe, K. ve Warneken, F. (2014). The developmental origins of fairness: The knowledge-behavior gap. Trends in Cognitive Sciences, 18(11), 559-561. https://doi.org/10.1016/j. tics.2014.08.003

Brosnan, S. F. (2006). Nonhuman species' reactions to inequity and their implications for fairness. Social Justice Research, 19(2), 153-185. https://doi.org/10.1007/PL00022136

Brosnan, S. F. ve de Waal, F. B. (2003). Monkeys reject unequal pay. Nature, 425(6955), 297-299. https://doi.org/10.1038/nature01963

Brosnan, S. F. ve de Waal, F. B. (2012). Fairness in animals: Where to from here?. Social Justice Research, 25(3), 336-351. https://doi.org/10.1007/s11211-012-0165-8

Brosnan, S. F. ve de Waal, F. B. (2014). Evolution of responses to (un) fairness. Science, 346(6207). doi: $10.1126 /$ science. 1251776

Burns, M. P. ve Sommerville, J. (2014). "I pick you": The impact of fairness and race on infants' selection of social partners. Frontiers in Psychology, 5(93), 1-10. http s://doi .org/10.3389/ fpsyg.2014.00093

Camerer, C. F. (2003). Behavioural studies of strategic thinking in games. Trends in Cognitive Sciences, 7(5), 225-231. https://doi.org/10.1016/S1364-6613(03)00094-9

Carpendale, J. I. (2000). Kohlberg and Piaget on stages and moral reasoning. Developmental Review, 20(2), 181-205. https://doi.org/10.1006/drev.1999.0500

Castelli, I., Massaro, D., Sanfey, A. G. ve Marchetti, A. (2014). "What is fair for you?” Judgments and decisions about fairness and Theory of Mind. European Journal of Developmental Psychology, 11(1), 49-62. https://doi.org/10.1080/17405629.2013.806264

Cesur, S. (2018) Ahlakın sosyal psikolojisi. İstanbul: Pales Yayınları.

Corbit, J., McAuliffe, K., Callaghan, T. C., Blake, P. R. ve Warneken, F. (2017). Children's collaboration induces fairness rather than generosity. Cognition, 168, 344-356. https://doi.org/10.1016/j. cognition.2017.07.006

Curry, O. S. (2016). Morality as cooperation: A problem-centred approach. T. K. Shackelford \& R. D. Hansen (Ed.), Evolutionary psychology. The evolution of morality içinde (s. 27-51). Basel, Switzerland: Springer International Publishing. https://doi.org/10.1007/978-3-319-19671-8_2

Damon, W. (1975). Early conceptions of positive justice as related to the development of logical operations. Child Development, 46(2), 301-312. https://doi.org/10.2307/1128122

Damon, W. (1981). The Development of Justice and Self-Interest during Childhood. Lerner, M. J. ve Lerner, S. C. (Ed.), The justice motive in social behavior: Adapting to times of scarcity and change içinde (s. 57-72). New York: Springer Press.

DesChamps, T. D., Eason A. E. ve Sommerville J. A. (2015). Infants associate praise and admonishment with fair and unfair individuals. Infancy, 21, 478-504. https://doi.org/10.1111/infa.12117

Engel, C. (2011). Dictator games: A meta study. Experimental Economics, 14(4), 583-610. https://doi. org/10.1007/s10683-011-9283-7

Fehr, E., Bernhard, H. ve Rockenbach, B. (2008). Egalitarianism in young children. Nature, 454(7208), 1079-1083. https://doi.org/10.1007/s10683-011-9283-7 
Fehr, E. ve Schmidt, K. M. (1999). A theory of fairness, competition, and cooperation. The Quarterly Journal of Economics, 114(3), 817-868. https://doi.org/10.1162/003355399556151

Forsythe, R., Horowitz, J. L., Savin, N. E. ve Sefton, M. (1994). Fairness in simple bargaining experiments. Games and Economic Behavior, 6, 347 - 369. https://doi.org/10.1006/game.1994.1021

Geraci, A. ve Surian, L. (2011). The developmental roots of fairness: Infants' reactions to equal and unequal distributions of resources. Developmental Science, 14(5), 1012-1020. https://doi. org/10.1111/j.1467-7687.2011.01048.x

Gilligan, C. (1982). In a different voice: Psychological theory and women's development. Cambridge, Mass: Harvard University Press.

Gummerum, M., Hanoch, Y., Keller, M., Parsons, K. ve Hummel, A. (2010). Preschoolers' allocations in the dictator game: The role of moral emotions. Journal of Economic Psychology, 31(1), 25-34. https://doi.org/10.1016/j.joep.2009.09.002

Güroğlu, B., van den Bos, W. ve Crone, E. A. (2009). Fairness considerations: Increasing understanding of intentionality during adolescence. Journal of Experimental Child Psychology, 104(4), 398-409. https://doi.org/10.1016/j.jecp.2009.07.002

Güth, W., Schmittberger, R. ve Schwarze, B. (1982). An experimental analysis of ultimatum bargaining. Journal of Economic Behavior \& Organization, 3(4), 367-388. https://doi.org/10.1016/01672681(82)90011-7

Haidt, J. (2001). The emotional dog and its rational tail: A social intuitionist approach to moral judgment. Psychological Review, 108, 814- 834. https://doi.org/10.1037/0033-295X.108.4.814

Haidt, J. ve Bjorklund, F. (2008). Social intuitionists answer six questions about moral psychology. W. Sinnott-Armstrong (Ed.), In Moral Psychology: Vol. 2. The cognitive science of morality: Intuition and diversity içinde (s. 181-217). Cambridge, MA: MIT Press.

Haidt, J. ve Graham, J. (2007). When morality opposes justice: Conservatives have moral intuitions that liberals may not recognize. Social Justice Research, 20(1), 98-116. https://doi.org/10.1007/ s11211-007-0034-z

Hamann, K., Bender, J. ve Tomasello, M. (2014). Meritocratic sharing is based on collaboration in 3-year-olds. Developmental Psychology, 50(1), 121-128. https://doi.org/10.1037/a0032965

Hamann, K., Warneken, F., Greenberg, J. R. ve Tomasello, M. (2011). Collaboration encourages equal sharing in children but not in chimpanzees. Nature, 476(7360), 328-331. https://doi.org/10.1038/ nature 10278

Harbaugh, W. T., Krause, K., ve Liday, S. (2003). Bargaining by children (University of Oregon Economics Working Paper, 2002-4). Eugene, OR: University of Oregon. http://dx.doi.org/10.2139/ ssrn.436504

İmamoglu, E. (1987). An interdependence model of human development. Ç. Kağıtçıbaşı (Ed.), Growth and progress in cross-culfural psychology içinde (s.138-145). Lisse, Holland: Swets \& Zeitlinger.

Kağıtçıbaşı, Ç. (2012). Benlik, aile ve insan gelişimi (kültürel psikoloji). İstanbul: Koç Üniversitesi Yayınları.

Kahneman, D., Knetsch, J., \& Thaler, R. (1986). Fairness and the Assumptions of Economics. The Journal of Business, 59(4), S285-S300. Retrieved May 23, 2021, from http:/www.jstor.org/ stable/2352761

Kajanus, A., McAuliffe, K., Warneken, F. ve Blake, P. R. (2019). Children's fairness in two Chinese schools: A combined ethnographic and experimental study. Journal of Experimental Child Psychology, 177, 282-296. https://doi.org/10.1016/j.jecp.2018.08.012

Kohlberg, L. (1976). Moral stages and moralization. Moral Development and Behavior, 31-53.

Kohlberg, L. (1981). The philosophy of moral development: Moral stages and the idea of justice. Cambridge, MA: Harper and Row. 
Kohlberg, L. (2008). The development of children's orientations toward a moral order. Human Development, 51(1), 8-20. DOI: 10.1159/000112530

Lane, I. M. ve Coon, R. C. (1972). Reward allocation in preschool children. Child Development, 43(4), 1382-1389. https://doi.org/10.2307/1127523

LoBue, V., Nishida, T., Chiong, C., DeLoache, J.S. ve Haidt, J. (2011). When getting something good is bad: Even three-year-olds react to inequality. Social Development, 20, 154-170. https://doi. org/10.1111/j.1467-9507.2009.00560.x

Lucca, K., Pospisil, J. ve Sommerville, J. A. (2018). Fairness informs social decision making in infancy. PloS One, 13(2). doi: 10.1371/journal.pone.0192848.

Malti, T., Gummerum, M., Keller, M., Chaparro, M. P. ve Buchmann, M. (2012). Early sympathy and social acceptance predict the development of sharing in children. PloS One, 7(12). doi: 10.1371/ journal.pone.0052017.

McAuliffe, K., Blake, P. R., Kim, G., Wrangham, R. W. ve Warneken, F. (2013). Social influences on inequity aversion in children. PLoS One, 8(12). doi: 10.1371/journal.pone.0080966.

McAuliffe, K., Blake, P. R., Steinbeis, N. ve Warneken, F. (2017). The developmental foundations of human fairness. Nature Human Behaviour, 1(2), 1-9. https://doi.org/10.1038/s41562-016-0042

McAuliffe, K., Blake, P. R. ve Warneken, F. (2014). Children reject inequity out of spite. Biology Letters, 10(12), 20140743. https://doi.org/10.1098/rsbl.2014.0743

Meristo, M., Strid, K. ve Surian, L. (2015). Preverbal infants' ability to encode the outcome of distributive actions. Infancy, 21(3), 353-372. https://doi.org/10.1111/infa.12124

Moore, C. (2009). Fairness in children's resource allocation depends on the recipient. Psychological Science, 20(8), 944-948. https://doi.org/10.1111/j.1467-9280.2009.02378.x

Nisan, M. (1984). Distributive justice and social norms. Child Development, 55(3), 1020-1029.

Paulus, M. (2015). Children's inequity aversion depends on culture: Across-cultural comparison. Journal of Experimental Child Psychology, 132, 240-246. https://doi.org/10.1016/j.jecp.2014.12.007

Piaget, J. (1932/1968). The moral development of the child. Kegan Paul: London.

Rai, T. S. ve Fiske, A. P. (2011). Moral psychology is relationship regulation: Moral motives for unity, hierarchy, equality, and proportionality. Psychological Review, 118(1), 57-75. https://doi. org/10.1037/a0021867.

Rizzo, M. T. ve Killen, M. (2016). Children's understanding of equity in the context of inequality. British Journal of Developmental Psychology, 34(4), 569-581. https://doi.org/10.1111/bjdp.12150

Rochat, P., Dias, M. D., Liping, G., Broesch, T., Passos-Ferreira, C., Winning, A. ve Berg, B. (2009). Fairness in distributive justice by 3 -and 5-year-olds across seven cultures. Journal of CrossCultural Psychology, 40(3), 416-442. https://doi.org/10.1177/0022022109332844

Schmidt, M. F. ve Sommerville, J. A. (2011). Fairness expectations and altruistic sharing in 15-monthold human infants. PloS One, 6(10). doi:10.1371/journal.pone.0023223.

Shaw, A., Choshen-Hillel, S. ve Caruso, E. M. (2016). The development of inequity aversion: Understanding when (and why) people give others the bigger piece of the pie. Psychological Science, 27(10), 1352-1359. https://doi.org/10.1177/0956797616660548

Shaw, A. ve Olson, K. R. (2012). Children discard a resource to avoid inequity. Journal of Experimental Psychology, 141(2), 382-395. https://doi.org/10.1037/a0025907

Sloane, S., Baillargeon, R. ve Premack, D. (2012). Do infants have a sense of fairness?. Psychological Science, 23(2), 196-204. https://doi.org/10.1177/0956797611422072

Smith, C. E., Blake, P. R. ve Harris, P. L. (2013). I should but I won't: Why young children endorse norms of fair sharing but do not follow them. PloS One, 8(3). doi:10.1371/journal.pone.0059510. 
Snarey, J. R. (1985). Cross-cultural universality of social-moral development: A critical review of Kohlbergian research. Psychological Bulletin, 97(2), 202-232. https://doi.org/10.1037/00332909.97.2.202

Sommerville, J. A. ve Ziv, T. (2018). The developmental origins of infants' distributive fairness concerns. K. Gray ve J. Graham (Ed.), Atlas of moral psychology içinde (s. 420-429). New York, New York: Guilford Press.

Takagishi, H., Kameshima, S., Schug, J., Koizumi, M. ve Yamagishi, T. (2010). Theory of mind enhances preference for fairness. Journal of Experimental Child Psychology, 105(1-2), 130-137. https://doi.org/10.1016/j.jecp.2009.09.005

Tepe, B. ve Aydınl1-Karakulak, A. (2019). Beyond harmfulness and impurity: Moral wrongness as a violation of relational motivations. Journal of Personality and Social Psychology, 117(2), 310 337. https://doi.org/10.1037/pspi0000169

Tomasello, M. (2018). The normative turn in early moral development. Human Development, 61(4-5), 248-263. https://doi.org/10.1159/000492802

Tomasello, M. ve Vaish, A. (2013). Origins of human cooperation and morality. Annual Review of Psychology, 64, 231-255. https://doi.org/10.1146/annurev-psych- 113011-143812

Trivers, R. L. (1971). The evolution of reciprocal altruism. The Quarterly Review of Biology, 46(1), 35-57. https://doi.org/10.1086/406755

Van Wolkenten, M., Brosnan, S. F. ve de Waal, F. B. (2007). Inequity responses of monkeys modified by effort. Proceedings of the National Academy of Sciences, 104(47), 18854-18859. https://doi. org/10.1073/pnas.0707182104

Xie, D., Pei, M. ve Su, Y. (2019). "Favoring my playmate seems fair": Inhibitory control and theory of mind in preschoolers' self-disadvantaging behaviors. Journal of Experimental Child Psychology, 184, 158-173. https://doi.org/10.1016/j.jecp.2019.03.004

Ziv, T. ve Sommerville, J. A. (2017). Developmental differences in infants' fairness expectations from 6 to 15 months of age. Child Development, 88(6), 1930-1951. https://doi.org/10.1111/cdev.12674 
